\title{
Significant Results . Space Makes a Difference Increasing Student Academic Engagement Levels
}

\author{
Lennie Scott-Webber, PhD \\ INSYNC: Education Research + Design, USA \\ Roger Konyndyk, PhD \\ Statistical Consulting, USA \\ Raechel French, MS \\ Research Associate, DLR Group, USA \\ Jim French, FAIA \\ DLR Group, USA
}

\begin{abstract}
Our team consisting of researchers, designers and a statistician are working to establish statistically reliable and valid survey instruments for use in post building occupancy for schools housing students and educators in grades nine to twelve. Two indexes are being created, a Student Engagement Index $\bigcirc$ and a Teachers Engagement Index $\mathbb{C}$. Our research question is, "Can we demonstrate that the design of the built environment for grades 9-12 impacts student academic engagement levels?" The sample for this survey was four high schools in the USA, in fall 2017. A time-honored PostOccupancy methodology was used. Findings had strong indicators showing the buildings' design makes a statistically significant difference regarding student academic engagement levels. Results were excellent on reliability and have convergent validity, with the exception of the last two questions. Statistical evidence from students and educators across all schools, grades, and genders that the buildings' designs impact their academic engagement levels $(\mathrm{p}<.0001)$. When active learning is used students recognize the impact. Concluded that for educators, the overall "culture" of the school is a far more important factor for teacher engagement than the physical layout. Seen as a real effect, all respondents acknowledged that the physical environment impacted engagement in their teaching and learning practices $(\mathrm{p}<.0001)$, significant result indicating that space makes a difference and increases student academic engagement levels.
\end{abstract}

Keywords: Active learning, student engagement, student success, classrooms, design, space matters, POE 


\section{Introduction}

Building a strong survey instrument measuring what one is questioning is not easy and takes time. Some say survey design is 'part art / part science.' This research team, comprised of researchers, designers and a statistician are working to establish statistically reliable and valid instruments. When finalized these are destined to be used post building occupancy for schools housing students and educators for grades nine to twelve. Thus, two indexes are being created - Student Engagement Index $\mathrm{C}$ and a Teachers Engagement Index@. Our research question, "Can we demonstrate that the design of the built environment for grades 9-12 impacts student academic engagement levels?" These measurements by the survey are taken post building occupancy. A post-occupancy evaluation measurement is a time-tested and important protocol to use in order to reach more valid conclusions on how the built environment impacts behaviors. This robust research technique is explained next.

An 'Alpha', or pilot phase was first conducted in spring of 2016 with one sample in the Midwestern USA. The methods and tactics used are shared in Figure 1 (see Figure 1). An onsite visit was conducted viewing all of the educational places. Then, focus interviews were conducted with architects, administrators, faculty members and students. These data were used to build upon previous work of others (Scott-Webber, Marshall-Baker \& Abraham, 2000; Scott-Webber, 2014) with a difference in age cohort studied - grades 912. The next segment developed was survey tool (Scott-Webber, Konyndyk, French, Lembke, \& Kinney, 2017). This tool was reviewed for reliability and validity and although findings revealed a statistical significance $(\mathrm{p}<.0001)$ in terms of students and faculty noting that the design of the building positively impacted student academic engagement factors. The research found survey fatigue and some questions that were not consistently answered. The next study conducted was this 'Beta,' or second pilot. The purpose of this next survey was to build on the Alpha. The Beta was tested on a convenience sample of four schools using grades 9-12 across the USA in the fall of 2017. This new survey addressed issues and concerns identified in the Alpha, and then aggregated the data across these different schools to build a more robust model of the instrument. The non-homogeneous sample allowed these researchers to garner different opinions by respondents and schools.

This type of social science research does not allow for designed experiments, limiting one's ability to draw definitive conclusions. Multiple factors influence respondents' answers. Knowing this limitation, we have worked to address issues of impact from the design of built environment, or physical space, at both the micro (or classroom) and macro (or overall building) levels, teaching practices, connection to school as 'community,' etc. 
acknowledging and then trying to determine perceptions of influence of the built place on these.

The ultimate goal here is to develop instruments that when completed will act as 'tools' for architectural firms in an education practice to continually test and improve design solutions - always looking to support student's academic successes. This article shares the research methodology, analysis techniques, findings, and conclusions allowing the reader an understanding of both the level of complexity and the work it takes to build an instrument that is then both reliable and valid.

\section{Method}

This research project used a Mixed-Method (Biddix, n.d.) research design. The survey, an online questionnaire facilitated by Survey Monkey, used a self-reporting (Garcia \& Gustavson, 1997) structure and users' perceptions for responses. Reliability and validity analyses were conducted. The number of usable respondents included for students $(n=462)$ and for educators $(n=137)$.

The theory underpinning this work is Social Practice Theory (Shove, Pantzar \& Watson, 2012). Briefly, these authors' suggested that social practices can be understood by thinking about the different elements that form social practices. The elements maybe abstract things that are made visible only when they come together in a particular social practice. An example relative to these authors' work for understanding behaviors in educational places - a whiteboard might be part of the technology of teaching, and it is associated with the cultural value of imparting and sharing information in the way we do teaching in many Western countries.

A Post-Occupancy Evaluation (POE) research technique was utilized to understand how the design of the built environment, or physical space impacts, in this case, student academic engagement behaviors. Why POE? It is a time-tested and valid protocol to explain perceived impacts of the built environment. Avdavan Tookaloo and Ryan Smith (2015) in their article, Post Occupancy Evaluation in Higher Education state, "Post occupancy evaluation of school buildings and educational environments has a nearly fifty-year history. The Building Performance Research Unit (BPRU) at the University of Strathclyde assessed over fifty comprehensive schools in Scotland in the late 1960s. This study provided one of the seminal examples of the post occupancy evaluation of school buildings. Methods that related space and its organization, to people's responses to the building, space use, costs, services and movement were all established. All these areas together show how wide POE can be... Studying and evaluating educational environments in academic institutions has always played a main role in the ongoing development of POE methods," p. 517. These authors further suggest that POE's act as a method of 
providing both subjective and objective feedback. These types of information can and should inform design planning and pedagogical practices throughout the building's life cycle (p. 518).

Hay, Flora, Watson \& Bradbury (2017) concur in their, 'PostOccupancy Evaluation In Architecture: Experiences And Perspectives From UK Practice' article that, "Within academic research, the post-occupancy agenda is well established and has produced a rich body of work on the complex interactions between design and people in occupied buildings (Jones \& Grigoriou, 2014; Watson, Evans, Karvonen, \& Whitley, 2016). The design quality literature has addressed a range of outcomes, including the impact of design on recovery rates (Ulrich, 2008), end-of-life care (Barnes, 2002); on attendance (Durán-Naracki, 2008) and learning in school environments (Barrett, Zhang, Davies, \& Barrett, 2015), on satisfaction (Armitage \& Murugan, 2013), and productivity in commercial workplaces (Baird, 2010; Leaman \& Bordass, 1999, pp.1-2). Further work by one of these authors has reviewed student engagement using post occupancy evaluation strategies building on this body of knowledge and the importance of using POE as a measurement strategy for understanding how the design of educational places impact student engagement behaviors (Scott-Webber, Mashall-Baker, \& Abraham, 2000; Scott-Webber, 2014; Nissim, Weissblueth, Scott-Webber \& Amar, 2016; Kilbourne, Scott-Webber \& Kapitula, 2017; Scott-Webber, Konyndyk, French, Lembke, \& Kinney, 2017).

In this second phase then of what we are calling the Student Engagement Index $($ (SEI) study, we used the analysis of the Alpha/pilot to design and develop the Beta. We were largely successful in eliminating the survey fatigue issues encountered in the Alpha, clarified some questions, and added others. The following methods and tactics were used for the protocols (see Figure 1).

Figure 1. Research Methods and Tactics.

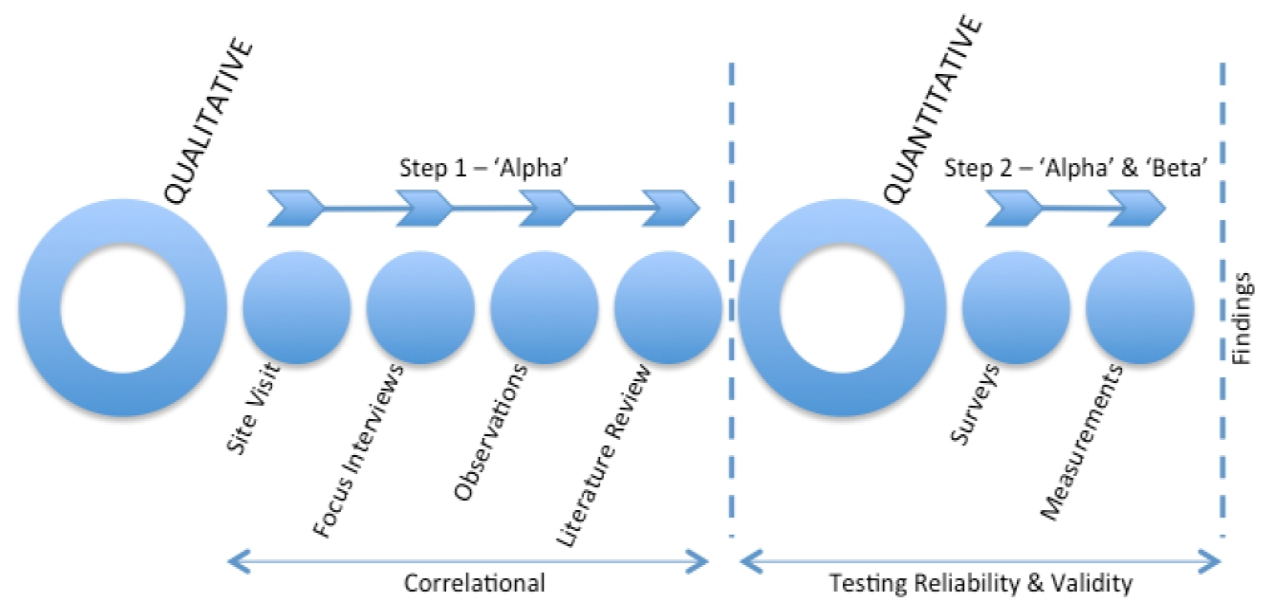


DLR Group's K12 Education Studio's team members acted as reviewers and pre-tested the online instrument. Two questionnaires were developed, one for each respondent base (i.e., (1) students and (2) educators) for grades 9-12. Criteria were: (a) to ensure the buildings were DLR Group constructed, (b) to be in use after 2004, and (c) if new, the building had to have been in use for at least one term, or three months. Questions addressed both the macro (i.e., OVERALL) and the micro (i.e., CLASSROOM) levels of the building's design. Multiple types of statistical analysis techniques were performed testing the research question and looking for reliability and validity within the questions and overall, with the end result being a survey proving to be measurably reliable and valid. In this Beta, we used a convenience sample of four high schools, coded A, B, D, E from multiple regions of the USA.

The questionnaire for the Beta had three segments including (1) questions specific to the classroom, (2) specific to the overall building's attributes and then (3) demographics. Questions were worded slightly differently to garner the particular user's perspective - students and educators. There were 12 questions and 72 sub-questions. An example helps explain. Question 1 asked about the importance of various teaching practices, while question 2 assessed overall feelings at the end of the school day. Questions 4 asked how well the classroom facilitated various teaching needs and practices. Questions 5 and 6 asked for ratings of the classroom and the building overall on several physical indoor quality attributes, while Question 7 asked what school values were indicated by the physical design, and Question 8 asked how well the school's design provided access to other people. Question 9 looked at the impact of building design on day-to-day learning activities. Questions 10 and 11 asked which teaching methods were used and where teaching takes place. Some demographic questions rounded out the survey.

\section{Analysis Techniques \\ Creation of Composite Variables}

A principal components analysis (Abdi \& Williams, 2010) was done on each question group. Except for the last two groups, the analysis indicated that a single component was adequate to describe the group. Further, all the individual question items had roughly equal loadings, indicating that the sum of the individual question items is a reasonable proxy for the group. Thus, if no items in a question group were skipped, then the composite variable for that group is simply the sum of the answers for that group. If exactly one item in a question group was skipped, then the average of the other questions was used to fill in that missing value before adding the items in the group to get the composite variable. If more than one item was skipped, the composite variable for that group was set to missing. 
The last two question groups gave us some difficulty, one which asked about where teaching takes place, and one which asked which teaching techniques were used. Students especially did not always seem to understand how to answer these questions, which were largely excluded from the analysis. These questions will be substantially revised in the next survey.

The set of questions from this survey used to develop the Student Engagement Index (SEI) was the sum of the items in question 2, "At the end of the school day, how often do you feel any of the following...(a) contributed to my team projects, (b) took care of my studies, (c) felt appreciated by my peers, (d) made good use of my time, (e) got teacher's help I needed, (f) did my best effort, $(g)$ challenged myself, and $(h)$ stimulated by what I am learning." The question items that were the best predictors of the Teacher Engagement Index (TEI) were numbers (a) and (g) with question 9 also doing fairly well. JMP software was used for the statistical analysis and graphics.

\section{Regression Using Composite Variables}

In each regression, the engagement index was initially regressed on one composite variable, plus school, grade level, gender, and where the student is from. Unnecessary variables were then dropped. Note that grade level was treated as a numeric variable in the regressions. This step both simplified the modeling and made any effect of grade level easier to detect. If a respondent skipped the Gender question, it was re-coded to 'Prefer not to say' for that person.

\section{Findings}

\section{Analysis}

The design of space matters - still. Findings in the Beta mirror ones from the Alpha and revealed that both students and educators agreed that the design of the built environment makes a difference relative to student academic engagement at both the macro level (i.e., 'Overall') and at the micro level (i.e., 'Classroom) at a high level of significance $(\mathrm{p}<.0001)$. The design of space matters but at times we had a different message from the two respondent groups. For students, the effects were the same across schools, while for educators the effect of the specific school was often more important than the factors the survey was attempting to measure. Like the Alpha survey, demographics were not important in assessing and modeling the results of the Beta.

\section{Does Space Make A Difference?}

The short answer is 'Yes.' But each user group expressed very different opinions in terms of how that response might be interpreted. 


\section{Comparing Students' and Educators' Perspectives.}

Q9: How much impact does the design of the building's physical spaces have on your... is a 'trigger' question for the survey for both students and educators. Why? It nets out the impact design is perceived to have on a range of multiple factors contributing to student academic success. Overall these findings are consistent with our Alpha and yes respondents do see a difference significantly at $\mathrm{p}<.0001$.

\section{Students' Academic Engagement Perceptions.}

Test the null hypotheses of mean $<=2.5$ (building design has at most a small to moderate impact) vs. the alternative hypothesis: mean $>2.5$. We have $\mathrm{p}<.0001$ using $\mathrm{T}$-tests shown in each of the items in Table 1 (see Table 1).

Table 1. Perceiving The Design Of Space Makes A Difference.

\begin{tabular}{|c|c|c|c|c|c|}
\hline \multirow[t]{2}{*}{ Q } & Question 9 & \multicolumn{2}{|c|}{ Educators } & \multicolumn{2}{|c|}{ Students } \\
\hline & $\begin{array}{c}\text { How much impact does the } \\
\text { design of the building's } \\
\text { physical spaces have on your... }\end{array}$ & $\begin{array}{l}\text { Mean } \\
\text { Value }\end{array}$ & $\begin{array}{l}\text { Significance } \\
\text { (T- test) }\end{array}$ & $\begin{array}{l}\text { Mean } \\
\text { Value }\end{array}$ & $\begin{array}{l}\text { Significance } \\
\text { (T- test) }\end{array}$ \\
\hline a & Motivation to attend classes & 3.21 & $\mathrm{P}=.0118$ & 2.81 & $\mathrm{P}<.0001$ \\
\hline $\mathrm{b}$ & Ability to do my best work & 3.40 & $\mathrm{P}<.0001$ & 2.96 & $\mathrm{P}<.0001$ \\
\hline $\mathrm{c}$ & $\begin{array}{l}\text { Perception that learning is } \\
\text { valued }\end{array}$ & 3.47 & $\mathrm{P}<.0001$ & 2.98 & $\mathrm{P}<.0001$ \\
\hline $\mathrm{d}$ & $\begin{array}{l}\text { Ability to move around be } \\
\text { deeply engaged in my learning }\end{array}$ & 3.73 & $\mathrm{P}<.0001$ & 3.06 & $\mathrm{P}<.0001$ \\
\hline $\mathrm{e}$ & $\begin{array}{l}\text { Perception that I can stay } \\
\text { connected to the school } \\
\text { community }\end{array}$ & 3.49 & $\mathrm{P}<.0001$ & 3.04 & $\mathrm{P}<.0001$ \\
\hline $\mathrm{f}$ & $\begin{array}{l}\text { Willingness to work to obtain } \\
\text { better grades/higher learning } \\
\text { outcomes }\end{array}$ & 3.34 & $\mathrm{P}<.0001$ & 3.07 & $\mathrm{P}<.0001$ \\
\hline
\end{tabular}

Educators’ Engagement Perceptions.

Test the null hypotheses of mean $<=3$ (building design has at most a moderate impact) vs. the alternative hypothesis: mean $>3$ (i.e., building design has more than just a moderate impact) (refer back to Table 1) using T-tests.

Teachers as a whole do see a real impact of the building design on their work, especially on their ability to move around to get students engaged. For each question item, the teachers see a greater impact from the building than the students do, even though the culture of the organization is more important than design to the educators.

\section{Specific Built Environment Factor Comparisons}

Here it is important to note that the built environment's factors and how they support one's 'learning/work' is perceived differently at times 
between students and educators. We'll highlight the challenges as seen by our respondents (see Figure 1). As you see, students believe that it is not easy to move around in the classroom to stay engaged and they don't find the furnishings comfortable. Both agree that the temperature for the rooms they are in is not at a comfortable level. These findings are consistent with the Alpha test.

Figure 1. Move to Engage - 'C' = Classroom. Q4: "How well do your classroom spaces provide you with the ability to...(d) move around to stay engaged?"

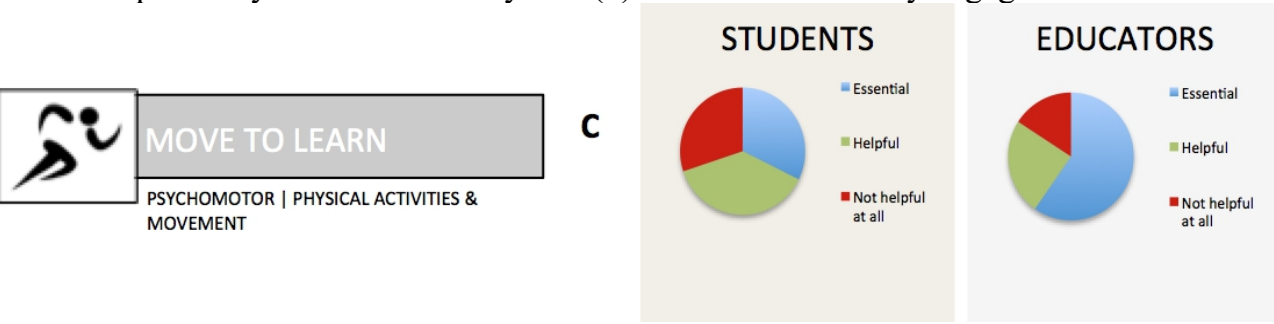

Figure 2. Examples of Environmental Quality Comparisons for Classroom.

ENVIRONMENTAL QUALITIES / CLASSROOM
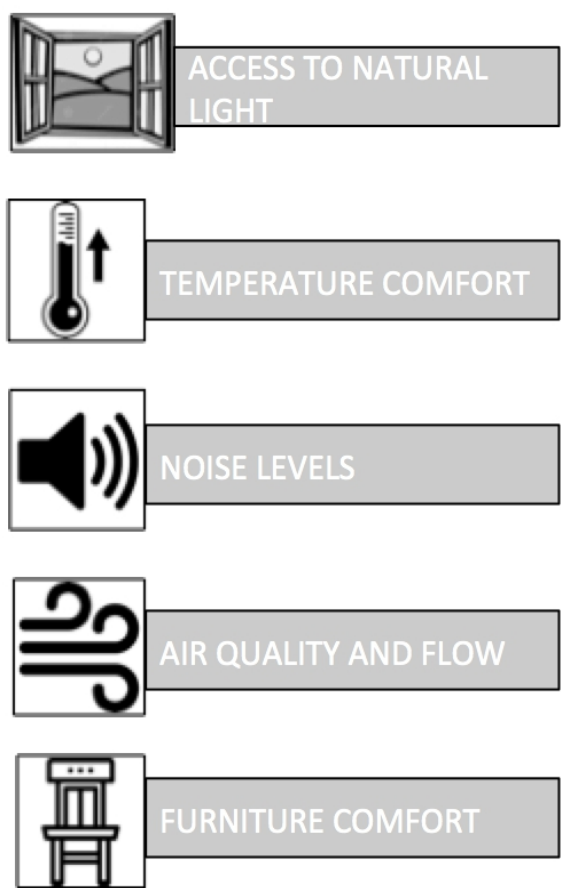

STUDENTS
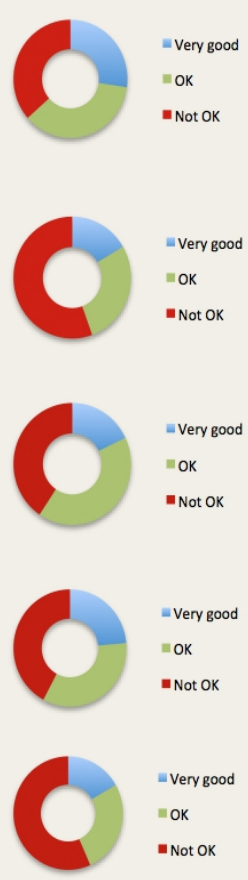

EDUCATORS
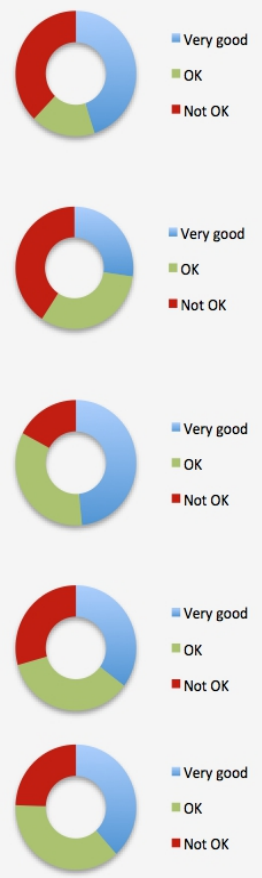

The graphs in Figures $1 \& 2$ show blue indicating a perception that the environmental quality in question is very good, green indicates it is just OK, and red suggesting that it is not OK. Student and educators perceptions are shared side-by-side for comparison purposes. 


\section{Complex Data}

\section{For Students}

Students provide similar results from both surveys (the Alpha and the Beta studies), a sign of overall validity. Students who gave higher ratings to their Classrooms tend to have higher engagement levels, and the effect is same across school, gender, grade, and origin, and it has a high degree of significance $(\mathrm{p}<.0001)$. The analysis seems to indicate that students can be highly engaged regardless of the amount of time in a non-classroom setting, but there are fewer unengaged students when non-classroom settings are used more, with a high degree of significance $(\mathrm{p}<.0001)$.

The more the students believe that the school values creativity, critical thinking, etc., overall, and also believe that the building provides good access to peers, technology, teachers, and allows them to easily engage in classroom activities tend to have higher overall academic engagement levels; the higher engagement level has a high degree of significance $(\mathrm{p}<.0001)$.

There is also a strong effect $(\mathrm{p}<.0001)$ from their perceived level of impact of the building has on their academic engagement levels. A regression model shows Rsquare $=.19$, with minor effects from gender $(p=.01321)$ and school ( $p=.0297)$ (see Figure 2). Taken by itself the regression for school ' $B$ ' would not be statistically significant, but when viewed against the other three that are virtually the same, it makes a statement and asks the question, "What is going on here?"

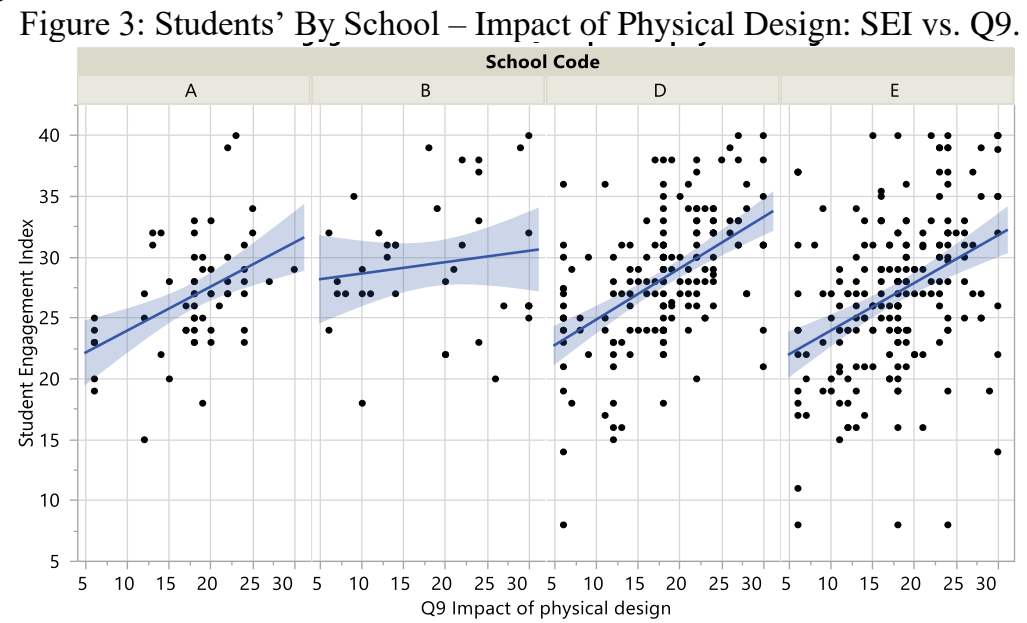

A cluster analysis was also performed. The numbers in the clustering for students were very interesting. When viewing the accompanying table (see Table 2), the top two lines 3 and 1 (higher engagement) had only 113 responses while the lower two lines 2 and 4 (less-engaged students) had 329 responses. When we look at clustering the students' responses in the graph by question we see four different lines (see Figure 3). The line sequenced 3 as blue, 1 as 
red, 2 as green, and 4 as orange. 3 yielded very high 'marks' all the way across all questions. 1 was mostly high all the way across except for dips for Qs $9 \&$ 10. 2 were flat-lined at a neutral viewpoint with a low drop for Q9, but up for Q10. 4 were very low all the way across except for a slightly higher tic for Qs 1,9 , and 10. Satisfaction with the physical environment goes hand-in-hand with student engagement.

Table 2: Cluster Means - Students.

\begin{tabular}{|c|c|c|c|c|c|c|c|c|c|c|}
\hline Cluster & Count & $\begin{array}{c}\text { Student } \\
\text { Engagement } \\
\text { Index }\end{array}$ & $\begin{array}{l}\text { Q1 } \\
\text { Importance } \\
\text { for } \\
\text { engagement } \\
\text { in learning }\end{array}$ & $\begin{array}{l}\text { Q4 How } \\
\text { well } \\
\text { classrooms } \\
\text { provide }\end{array}$ & $\begin{array}{l}\text { Q5 Rate } \\
\text { Classroom } \\
\text { Design } \\
\text { Aspects }\end{array}$ & $\begin{array}{c}\text { Q6 } \\
\text { Rate } \\
\text { Bldg } \\
\text { Overall }\end{array}$ & $\begin{array}{l}\text { Q7 } \\
\text { What } \\
\text { does } \\
\text { school } \\
\text { value? }\end{array}$ & $\begin{array}{c}\text { Q8 } \\
\text { School's } \\
\text { physical } \\
\text { design } \\
\text { provides... }\end{array}$ & $\begin{array}{c}\text { Q9 } \\
\text { Impact } \\
\text { of } \\
\text { physical } \\
\text { design }\end{array}$ & $\begin{array}{l}\text { Q10 } \\
\text { Non- } \\
\text { Lecture } \\
\text { teaching } \\
\text { methods }\end{array}$ \\
\hline 1.red & 82 & & 27.3885 & & & 29.4425 & 29.7997 & 19.0732 & 22.1829 & 10.9919 \\
\hline 2. green & 178 & 27.6541 & 25.6477 & 34.2247 & 23.4109 & 24.9767 & 26.0891 & 16.4888 & 16.4787 & 11.1948 \\
\hline 3.blue & 51 & & 31.4986 & 43.7495 & 32.2353 & 34.5294 & 34.7031 & 22.4706 & 26.4118 & 15.4902 \\
\hline 4.orange & 151 & 23.6414 & 23.9754 & 27.7439 & 16.6878 & 18.6727 & 20.7644 & 12.5033 & 14.4967 & 9.1192 \\
\hline
\end{tabular}

Figure 4: Hierarchy Clustering - Students.

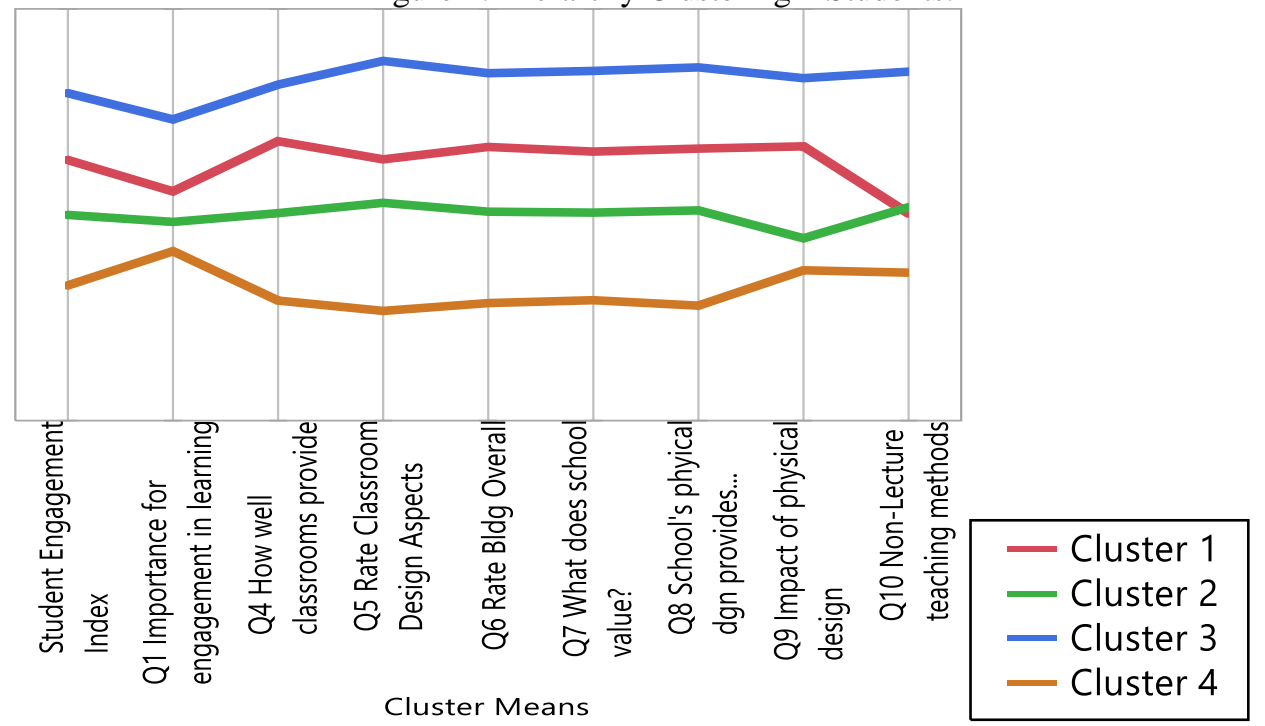

\section{Analysis of Questions - Student Survey}

Q.4. A question-by-question analysis was conducted. Here we will share some of the important highlights of those analyses. We will look at question \#4, then a series of questions that relate to movement and learning, and finally compare questions 5 and 6 - the environmental aspects between the classroom and the overall building.

We have a very definite effect on the student engagement index from question 4 (How well do your classroom spaces provide you with the ability to...), with Rsquare $=.30$ and $\mathrm{p}<.0001$. Grade level has a marginal effect, with engagement decreasing slightly in the higher grades, while the demographic variables had no effect. The more favorably students rate their 
classrooms; the higher their engagement tends to be and the more they feel their learning outcomes go up. School had no measurable effect here. Design of space makes a difference to students (see Table 3).

Table 3: Parameter Estimates.

\begin{tabular}{|c|c|c|c|c|}
\hline Term & Estimate & Std Error & t Ratio & Prob $>|t|$ \\
\hline Intercept & 14.793141 & 1.116149 & 13.25 & $<.0001^{*}$ \\
\hline Q4 How well classrooms provide & 0.4214845 & 0.030165 & 13.97 & $<.0001^{*}$ \\
\hline What grade are you in currently? & 0.733862 & 0.25722 & -2.85 & $0.0045^{*}$ \\
\hline
\end{tabular}

Movement.

The focus on movement concentrated on three variables:

- $\quad$ Q1 Move about to learn

- $\quad$ Q4 Move around to stay engaged

- $\quad$ Q9 Ability to move around to be deeply engaged in my learning.

The items in Q1 were positively correlated with each other. Students who believe that one of these items is important for their learning tend to believe that the other items in question 1 are important, too. Yet there was a weakness in the effect between believing that being able to move about to learn was important and the answers to the items in other question groups.

For Q4, students who believe that the classroom space enables them to move around to stay engaged are more likely to be stimulated by what they are learning and are more likely to be engaged overall. Not surprisingly, they are somewhat more likely to see the school's design as giving them access to their peers and teachers (i.e., question 8).

In Q9, 'How much impact does the design of the building's physical spaces have on your...ability to move around to be deeply engaged in my learning?' Students who perceive that the building's design has an impact on their ability to move around to be engaged are more likely to believe that the school values critical thinking and collaboration.

\section{Comparing Questions 5 and 6.}

Questions $5 \& 6$ are about the indoor environmental qualities $(5=$ classroom \& $6=$ overall). The environmental factors queried included: noise, lighting, temperature, access to natural light, feeling safe, comfortable furniture, inviting space and air flow. At the 'classroom' level all were rated from good-to-very good, or good-to-excellent except these - temperature, which was poor-to-good, comfortable furniture poor-to-good and airflow was fair-to-good. At the 'overall' level responses were virtually the same as the classroom ones.

If we regress the student engagement index on question 5, the model fits well, with Rsquare $=.23$. Gender may have a very slight effect $(p=.089)$, with females having slightly higher engagement, and 'Prefer not to say' the 
lowest. Other demographic variables have no effect. The best model to use would be using only Question 5 ( $\mathrm{p}<.00001)$ and no demographic variables. Thus we conclude that students who give higher ratings to their classrooms tend to have higher engagement, and the effect is similar across school, gender, grade, and origin (see Figure 6). Regression results for Q6 are very similar to those of question 5. Here Rsquare $=.22$, with a minor effect due to gender ( $\mathrm{p}$ $=.01362)$, and a good effect due to Q6 $(\mathrm{p}<.00001)$, with a reasonable overall fit (see figure 5).

Figure 5. Regression Plot - Student Engagement Index vs. Q5 \& Q6.
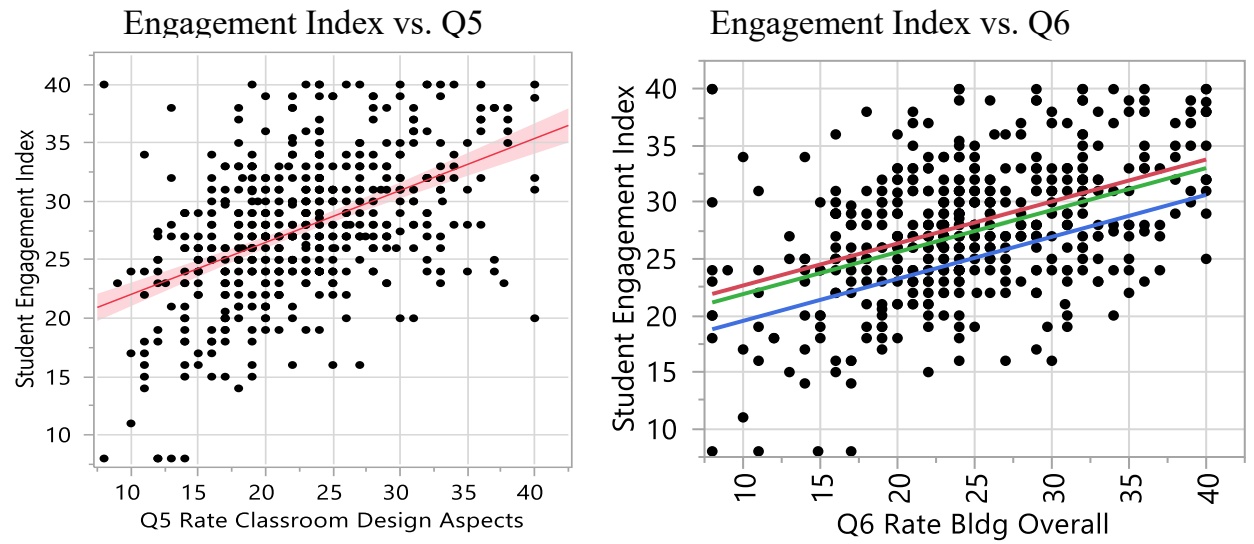

- Line of Fit for What is your gender?[Female]

- Line of Fit for What is your gender?[Male]

- Line of Fit for What is your gender?[Prefer not to say]

\section{Summary For Students}

The student piece of the Beta is quite consistent with that of the Alpha. The data consistently showed that the quality of the physical places where students learn, both the classroom and the building as a whole, is positively correlated with their level of engagement in their studies, and the effect is consistent across schools, gender, grade level, and where the student is from. The analysis results and the validity findings mirrored the Alpha, while the reliability was even better than with the Alpha, for questions 1 9. There were reliability and validity issues with the last segment of the survey, which will be addressed in the next iteration. With a nonhomogeneous group in the Beta, the overall good results and their similarity to those of the Alpha adds credibility to the design of the instrument.

\section{For Educators}

There is a very significant difference in the level of teacher engagement from school to school, which cannot be explained by other factors considered in this survey. The quality of the school administrators, school culture and the level of parental support are just three examples of other factors 
that might well play a role here that this survey cannot explain. Gender, level of education, and where a teacher is from had no detectable influence on the level of teacher engagement as measured by this survey.

The set of questions used to develop the Teacher Engagement Index (TEI) is the sum of the numeric values of all the items in question \#2. Q.2 'At the end of a school day, how often do you feel any of the following about your students... Students contributed to their team projects, and students took care of their studies?'

\section{Impact of Physical Design}

Regressing the TEI on question 9 ("How much impact does the design of the building's physical spaces have on your...") yields a fairly good value of Rsquared, indicating that those teachers who see an impact from the building's design tend to be more engaged than those who do not. Allowing the effect of question 9 to be different for each school did not significantly improve the fit of the model of the Teachers Engagement Index (TEI) (see Figure 6). As with the student's information looking at SEI (Student Engagement Index) with Q9, the reader also begins to see the impact of school on the findings. Taken by itself the regression for school 'B' would not be statistically significant, but when viewed against the other three that are virtually the same, it makes one wonder what is different about that school.

Figure 6. Educator Impact of Physical Design - TEI vs. Q9.

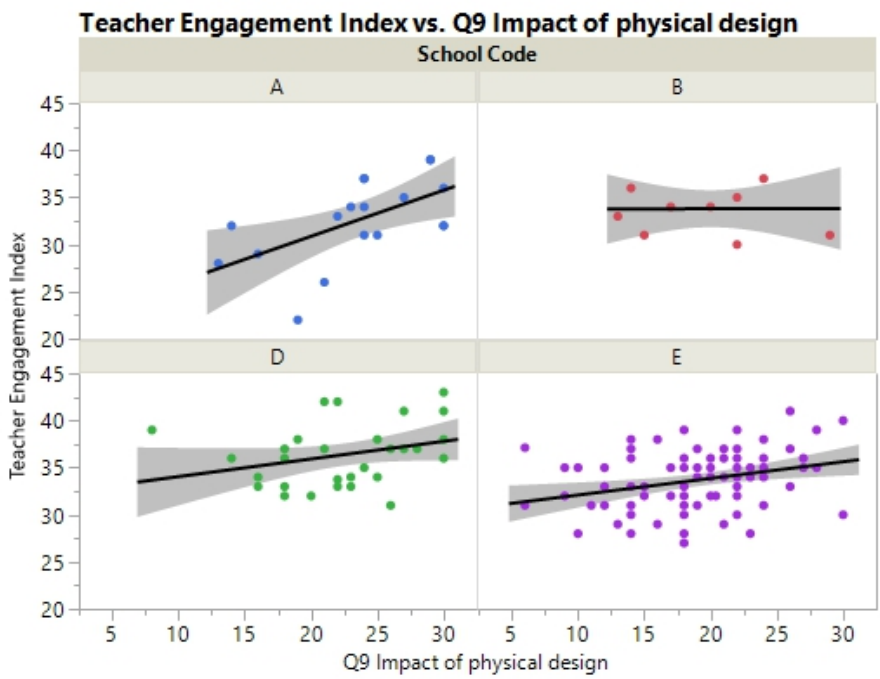

For educators, we expected to see a stronger relationship between satisfaction with the building's design and the teacher engagement index, particularly related to the classroom. We did not get statistical significance here. A cluster analysis begins to help explain some of these discrepancies and perhaps what confounded our result. 
This cluster analysis yielded four clusters of educator responses, with the cluster means shown by the four lines in Figure 7. The top to bottom line sequenced 4 as tan, 1 as red, 3 as blue, and 2 as green. 4 yielded very high 'marks' all the way across all questions. Red line 1 is relatively neutral across all questions. Then, the lines $3 \& 2$ become erratic. Blue gives its highest marks for the overall building design, dips and then comes back up some for Q11 using the 'other' types of teaching spaces. Now, look at cluster 2, the green line. It represents 8 teachers who are highly engaged but have a very low opinion of the school's physical layout. They have the highest engagement of any cluster, but the lowest ratings for questions $4,5,6,7$, and 8 . The total number of responses were $n=137$. When one views the accompanying table (see Table 4), the number of responses and their variance of expressed opinions were interesting: 48 made up the top line \#4 or tan, 55 for \#1 or red, 26 for blue, and only 8 for green.

Thus, the most engaged cluster, of only 8 teachers, gave the lowest ratings to the classroom and overall building features. One of the two lowerengagement clusters, with 26 teachers, gave fairly high ratings to the classroom and building features. For a minority of surveyed teachers, satisfaction with physical surroundings is not linked to engagement, as measured by this survey. For the other two clusters, 103 of the total 137 teachers, higher ratings of the physical surroundings were paired with higher levels of engagement.

Table 4. Cluster Means - Educator.

\begin{tabular}{|c|c|c|c|c|c|c|c|c|c|c|c|}
\hline Cluster & Count & $\begin{array}{l}\text { Teacher } \\
\text { Engage } \\
\text {-ment } \\
\text { Index }\end{array}$ & $\begin{array}{l}\text { Q1 } \\
\text { Importance } \\
\text { for } \\
\text { Engagement }\end{array}$ & $\begin{array}{l}\text { Q4 How } \\
\text { well } \\
\text { classrooms } \\
\text { provide }\end{array}$ & $\begin{array}{l}\text { Q5 Rate } \\
\text { Classroom } \\
\text { Design }\end{array}$ & $\begin{array}{l}\text { Q6 } \\
\text { Rate } \\
\text { Bldg } \\
\text { Overall }\end{array}$ & $\begin{array}{l}\text { Q7 } \\
\text { What } \\
\text { does } \\
\text { school } \\
\text { value? }\end{array}$ & $\begin{array}{l}\text { Q8 } \\
\text { School's } \\
\text { physical } \\
\text { design } \\
\text { provides }\end{array}$ & $\begin{array}{l}\text { Q9 } \\
\text { Impact of } \\
\text { physical } \\
\text { design }\end{array}$ & $\begin{array}{l}\text { Q10 } \\
\text { Non- } \\
\text { Lecture } \\
\text { teaching } \\
\text { methods }\end{array}$ & $\begin{array}{l}\text { Q11 } \\
\text { Breakout+ } \\
\text { Outside+ } \\
\text { Library }\end{array}$ \\
\hline 1.red & 55 & 32.07 & 29.16 & 35.51 & 22.88 & 24.02 & 24.99 & 15.15 & 17.55 & 12.07 & 5.48 \\
\hline 2.green & 8 & 37.25 & 35.63 & 27.50 & 16.88 & 16.00 & 23.00 & 11.50 & 21.13 & 11.63 & 5.00 \\
\hline 3.blue & 26 & 33.65 & 27.92 & 39.12 & 29.12 & 32.00 & 26.58 & 16.92 & 19.02 & 9.62 & 5.04 \\
\hline 4.orange & 48 & 36.23 & 32.50 & 43.71 & 31.65 & 33.34 & 32.98 & 20.33 & 25.40 & 13.40 & 6.13 \\
\hline
\end{tabular}


Figure 7. Cluster Analysis - Educator.

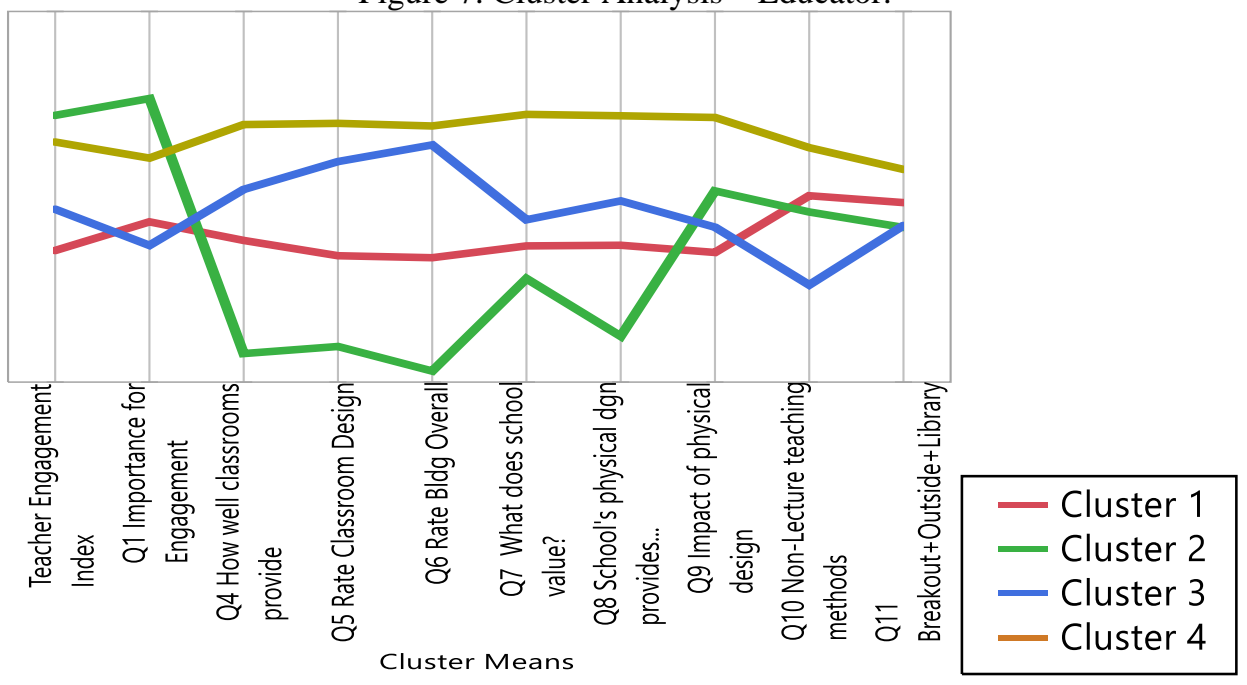

\section{Analysis of Questions - Educator Survey}

Question 1, 'For your students to be deeply engaged in their learning in the classroom, how important is it for you to have them...?' We see statistical significance $p<.00001$. The more the teachers see the items in question 1 as being important for the students, the more engaged the teachers are likely to be. Allowing the slopes of the lines to be different for each school did not significantly improve the fit of the model; the rise in teacher engagement with the ratings of the importance of the items in question 1 is basically the same for each school.

Table 5. Impact of Physical Design.

\begin{tabular}{|c|c|}
\hline Significant Variables & Teacher Engagement Index \\
\hline Q1 Importance of factor for student engagement & $\mathrm{P}<.00001$ \\
\hline School Code & $\mathrm{P}=.00003$ \\
\hline Rsquare & $.26, \mathrm{p}<.0001$ \\
\hline
\end{tabular}

Figure 8. Regression Plot of Q1 vs. Teacher Engagement Index.

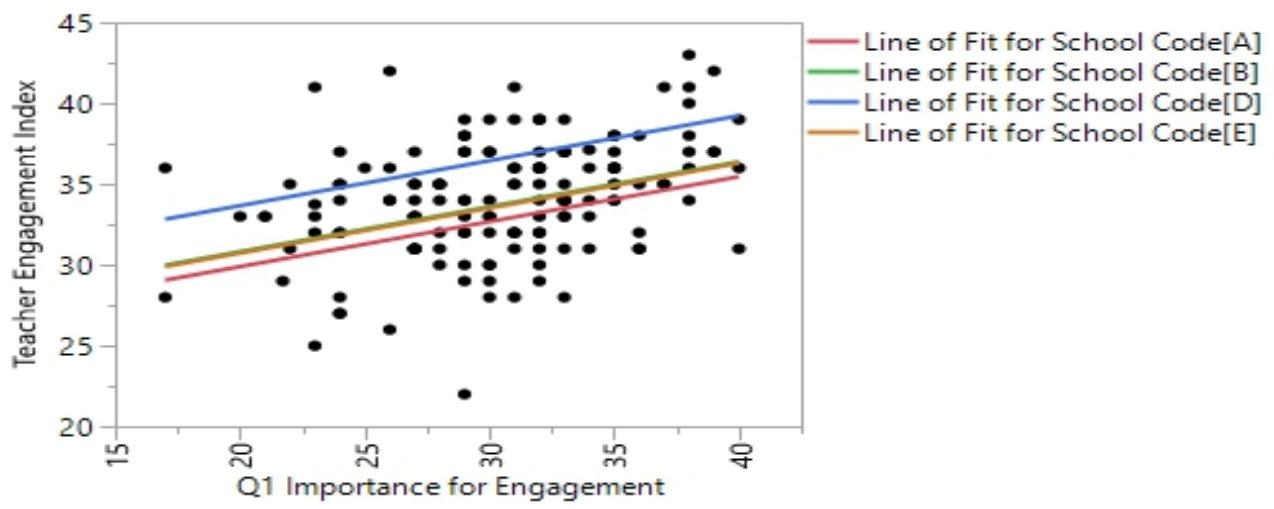


Question 4, 'How well do your classroom spaces provide you with the ability to...?' Note that the effect due to the school was actually stronger than that of the ratings of the classroom. Teacher engagement does rise with the teacher's ratings of the classroom, but the effect is not as strong a one might expect. Allowing different slopes for each school does not provide a statistically significant improvement in the model (see Table 6 and refer back to Figure 9).

Table 6. Q4, How well do your classroom spaces provide you with the ability to...?

\begin{tabular}{|c|c|}
\hline Significant Variables & Teacher Engagement Index \\
\hline School Code & $\mathrm{P}=.00137$ \\
\hline Q4 How well classrooms provide... & $\mathrm{P}=.00471$ \\
\hline Rsquare & $.17, \mathrm{p}<.0001$ \\
\hline
\end{tabular}

See Figure 10 for a school-by-school overview between the Teacher Engagement Index and Q4 in terms of how well the micro, or classroom environment provided for them.

Figure 9. Regression Plot for the Teacher Engagement Index vs. Q4.

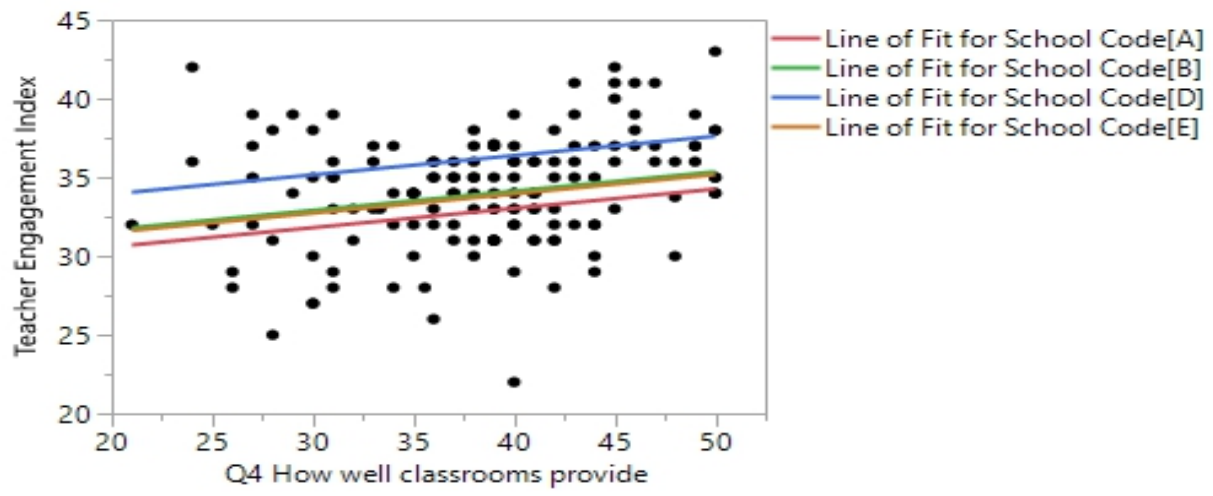

Figure 10. Teacher Engagement Index vs. Q4 How Well Classrooms Provided For...

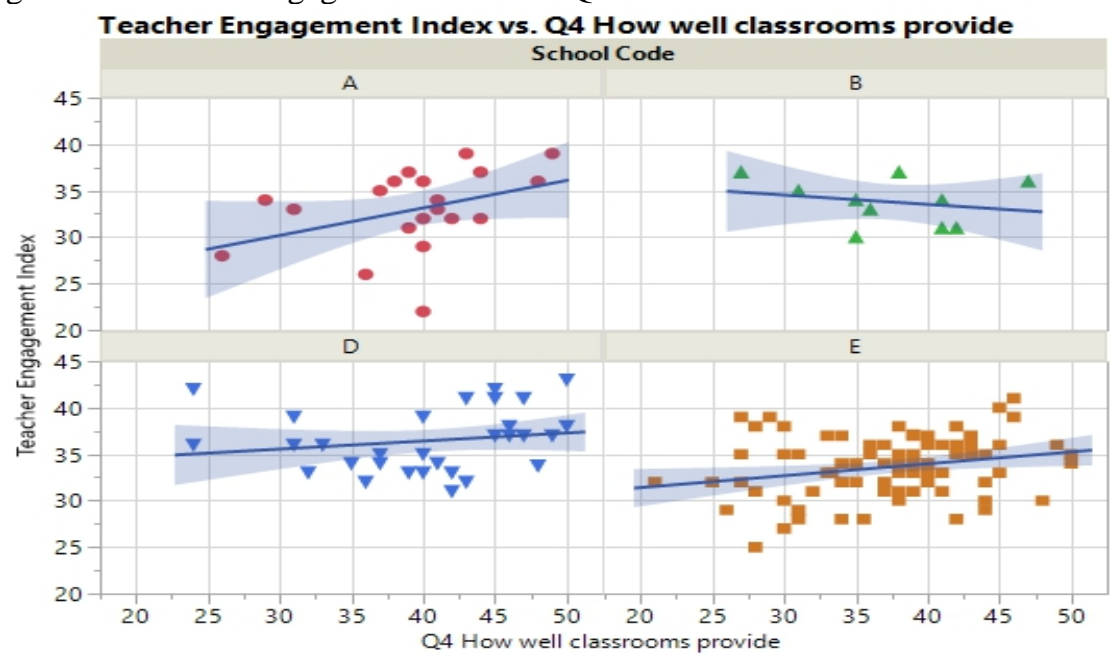




\section{By Movement}

Teachers who believe that their classroom provides them the ability to move around to keep students engaged (Q4) (refer back to Figure 10) also tend to believe that...

- $\quad$ They can configure/reconfigure the classroom as needed;

- The school values creativity, critical thinking, and collaboration;

- The school's physical design provides them with 'Access to my students for mentoring and feedback' and 'Ability to have my students engage in classroom activities'; and

- $\quad$ The building's physical spaces have an impact on their 'Ability to move around to get students deeply engaged in their learning.'

Similarly, teachers who believe that their classroom provides them with the ability to 'Configure and reconfigure classroom furniture as needed' also tend to believe that...

- $\quad$ Their classroom provides them the ability to move around to keep students engaged;

- $\quad$ The school values creativity and collaboration; and

- $\quad$ The school's physical design provides them with 'Access to my peers for collaborating,' 'Access to my students for mentoring and feedback,' and 'Ability to have my students engage in classroom activities.'

Teachers who believe that the building's physical spaces have an impact on their 'Ability to move around to get students deeply engaged in their learning' (question 9) are more likely to believe that...

- $\quad$ Their classroom provides them the ability to move around to keep students engaged;

- $\quad$ The school value critical thinking and collaboration;

- $\quad$ The school's physical design provides them with 'Access to my peers for collaborating' and 'Access to my students for mentoring and feedback.'

- The building's physical spaces have an impact on their 'Perception that I can stay connected to the school community' and their 'Willingness to work to obtain better grades/higher learning outcomes.'

\section{Qs 5 and 6.}

Questions 5 and 6 each have a set of questions under the major topic. Q5's is relative to the classroom and Q6's is in reference to the overall building environment's environmental qualities. The educators across the four schools are in sync relative to the building's qualities at both the micro, or classroom, and macro, or overall building levels. There are some exceptions. These exceptions include for the classroom: $40.7 \%$ rate the temperature control in the classrooms to be either fair or poor. $37.8 \%$ believe the access to natural light is again at a fair or poor level. At the overall level educators concur 
improvement could be made for the temperature (31.8\%) comfort. We have shared that educators and students often do not agree on these perceptions. But both concur on temperature discomfort.

\section{Summary for Educators}

The teacher survey surprised us, in that the physical environment seemed to matter much less as discovered in this Beta than with the Alpha. To develop a robust Teachers Engagement Index, we have more adjustments to make in the next version. The clarity of the Alpha was not present here in the Beta and therefore, an analysis of what worked, what changed, and what didn't work is needed. An item that emerged in the Beta was the importance of the 'culture' of the school for the educators. This finding is understandable and explainable logically, but now there is added 'proof' of the need to address this item in the next version. What was not clear is why educators did not place more importance on their individual classroom designs. Perhaps the issue was that this survey did not give as good an indicator of teacher engagement as we had hoped; the measure of teacher engagement will be changed in the next survey.

\section{Testing Reliability and Validity}

The findings revealed that this survey proved to be both reliable and valid. This text will share the separate analysis of the students and then the educators.

\section{Student Survey Reliability}

For questions $1-9$, all values of Cronbach's alpha are .83 or higher on the student survey, indicating excellent reliability. Questions 10 and 11, about where teaching takes place and the types of teaching techniques used, were designed with the expectation that the answers to the various items within those question groups would be negatively correlated, meaning that Cronbach's alpha would not be useful for those two questions. However, the final segments have issues to be addressed in the next iteration.

\section{Validity}

We have very good evidence of convergent validity, apart from questions 10 and 11. For example, one would expect that ratings of the classroom would be similar to ratings of the building overall, and they are. One would expect student satisfaction with the physical facilities to translate into somewhat higher levels of engagement, and this was indeed the case, as shown by the regression analyses of the composite variables formed from the various question groups against the 'Student Engagement Index,' which was 
the sum of the items in question 2. The effects the various question areas on engagement were consistent across schools, gender, and grade level. No interaction terms were required in modeling.

Question groups 4 and 5, both relating to classroom design, were also well correlated with each other, another evidence of convergent validity. The composite variables formed by taking the sums of the items each group have a correlation of. 658 , and all the individual items are positively correlated with each other.

A look at question 1 gives evidence of discriminant validity. One would expect that students who are aware of issues that might affect engagement would also be more engaged, but since the question is only theoretical, not tied to any actual situations or conditions currently being experienced, one would not look for a strong correlation. This is exactly what happened; the regression analysis shows that engagement tends to rise a bit with the importance that students assign to the issues in question 1, but the Rsquared value of .10 is the weakest among all the regressions done. Thus, we have good evidence of both convergent and discriminant validity in the student survey, outside of questions 10 and 11 - the last segments.

Questions 10 (teaching methods used) and 11 (where teaching takes place) did not work as hoped. Some students answered 'Almost all the time' or 'Most of the time,' to each item in the question group, a clear impossibility. These two questions will have to be revised on any future survey, if they are to be useful.

\section{Educator Survey Reliability}

Like the student survey, we have very good reliability results for questions $1-9$; all values of Cronbach's alpha are .75 or higher on those questions. Questions 10 and 11 did not have a problem with respondents giving essentially the same answer to each item, unlike the student survey. However, those questions were not designed to give high reliability numbers, and values of Cronbach's alpha were quite low for questions 10 and 11 , as expected. The other question groups were designed with the expectation that the answers would be positively correlated; questions 10 and 11 were designed with the expectation that the answers would be negatively correlated. A reliability measure is not useful in that situation.

\section{Validity}

Like the student survey, the two questions about satisfaction with the classroom (questions 4 and 5) were strongly correlated, with the composite variables for each having a correlation coefficient of .553. Likewise, in questions 5 and 6 , in which the same question items appear for both the 
classroom and the building overall, each question item has its strongest correlation with the corresponding item in the other question group, evidence of convergent validity.

\section{Teacher Engagement}

Results from the educator survey were more complex than those from the student survey. A one-way ANOVA of the Teacher Engagement Index using the school as the independent variable yields an Rsquared value of .12 with $\mathrm{p}=.0003$; there are real differences in teacher engagement from school to school. Overall, the question items seemed to have less impact on teacher engagement than in the alpha survey. Unlike the student survey, results were not always consistent from school to school. For example, regressing the TEI on each individual school on questions 5 and 6 (ratings of classroom and building) for one school yielded a significant p-value (under .04) and Rsquared values of .21 and .25 , respectively, but absolutely no effect at all for the other three schools.

The question items that were the best predictors of the Teacher Engagement Index were numbers 1 (importance of items for student engagement), 7 (what does the school value) and 9 (impact of the physical design). None of these three questions is directly related to the physical space of the building. Questions 4, 5, 6, and 8, which are about satisfaction with the physical surroundings, were all less important to teacher engagement than school-to-school differences. Based on these results, one would conclude that the overall "culture" of the school is more important for teacher engagement than the physical layout. This message is consistent within the educator survey, and that consistency is evidence of overall validity. However, this message in this survey is somewhat different from that of the Alpha. As noted above, changes will be made in the next survey to attempt to gain more clarity. We do have evidence of discriminant validity here, in that the teachers consistently distinguished between the school "culture" and the physical environment, in terms of the effects on their levels of engagement - and that evidence is a good thing.

As with the student survey, there were some issues with the last two groups, although these questions worked better with the teachers than with the students. An anomalous result was that for question 11 ("Now, tell us where teaching takes place?"), for two of the schools there was no relationship between the amount of teaching time done outside the classroom and teacher engagement; for one schoolteacher engagement increased with time spent outside the classroom, and with the fourth school it decreased. We have more work to do here to insure clarity of the questions. 


\section{Limitations And Conclusion}

The results of this survey, with just four schools, are not generalizable to an entire nation. However, many results were also found in the Alpha and therefore we believe once we have a larger sample size and aggregate that data, definitive statements will be back up our current conclusions.

Our goal for this research was to build a reliable and valid instrument that gets at answering our research question, "Can we demonstrate that the design of the built environment for grades 9-12 impacts student academic engagement levels?" We have now completed two phases in this study. We had four high schools as a convenience sample from different areas of the USA for this Phase II - Beta study. The number of usable respondents included for students $(n=462)$ and for educators $(n=137)$. We have reviewed both the extensive quantitative data in great detail. The Findings reveal...

- $\quad$ Results were excellent on reliability and have convergent validity except for questions 10 and 11 . These two questions will have to be reevaluated/edited for the next round.

- $\quad$ Agreement from students across all schools, grades, and genders that the buildings' designs impact their academic engagement levels at a level of significance $(\mathrm{p}<.0001)$.

- $\quad$ Agreement from educators that the design of the built spaces positively impacts their students' engagement levels.

- Dominant teaching practice was lecture, which is unfortunate to see given the work done on active learning. However, when active learning is incorporated students recognize the impact.

- $\quad$ Conclude that for educators, the overall 'culture' of the school is a far more important factor for teacher engagement than the physical layout. However, we believe we have to change our questions to further understand 'engagement.'

- $\quad$ Seen as a real effect, all respondents seeing acknowledged that the physical environment impacted engagement in their teaching and learning practices $(\mathrm{p}<.0001)$.

Reliable and valid instruments were built, but a third round is needed to ensure each question is the best it can be.

NOTE: Acknowledgement: With thanks to DLR Group's K12 Education Practice for sponsoring this research. Also, thanks to our four high schools in the USA who participated in the study.

\section{References:}

1. Abdi, H. \& Williams, L. J. (2010). Principal component analysis. Overview, (2). TX: University of Texas at Dallas, p. 433. Retrieved from: https://www.utdallas.edu/ herve/abdi-awPCA2010.pdf 
2. Armitage, L., \& Murugan, A. (2013). The human green office experience: Happy and healthy or sick and frustrated? Australian and New Zealand Property Journal, (4), pp. 35-41. In Rowena Hay, Flora Samuel, Kelly J. Watson \& Simon Bradbury (2017): Post-occupancy evaluation in architecture: experiences and perspectives from UK practice, Building Research \& Information, UK: Routledge a Taylor \& Francis Group, pp. 1-14. DOI: 10.1080/09613218.2017.1314692

3. Baird, G. (2010). Sustainable buildings in practice: What the users think. London: Routledge. In Rowena Hay, Flora Samuel, Kelly J. Watson \& Simon Bradbury (2017): Post-occupancy evaluation in architecture: experiences and perspectives from UK practice, Building Research \& Information, UK: Routledge a Taylor \& Francis Group, pp. 1-14. DOI: 10.1080/09613218.2017.1314692

4. Barnes, S. (2002). The design of caring environments and the quality of life of older people. Ageing \& Society, (22), pp. 775-789. doi:10.1017/S0144686X02008899. In Rowena Hay, Flora Samuel, Kelly J. Watson \& Simon Bradbury (2017): Post-occupancy evaluation in architecture: experiences and perspectives from UK practice, Building Research \& Information, UK: Routledge a Taylor \& Francis Group, pp. 1-14. DOI: 10.1080/09613218.2017.1314692

5. Barrett, P., Zhang, Y., Davies, F., \& Barrett, L. (2015). Clever classrooms.

Retrieved

from

http://www.salford.ac.uk/cleverclassrooms/1503-Salford-Uni-ReportDIGITAL.pdf. In Rowena Hay, Flora Samuel, Kelly J. Watson \& Simon Bradbury (2017): Post-occupancy evaluation in architecture: experiences and perspectives from UK practice, Building Research \& Information, UK: Routledge a Taylor \& Francis Group, pp. 1-14. DOI: 10.1080/09613218.2017.1314692

6. Biddix, J. P. (n.d.). Mixed method research design. Research rundowns - uncomplicated reviews of educational research methods. MI: University of Missouri. Retrieved from: https://researchrundowns.com/mixed/mixed-methods-researchdesigns/

7. Durán-Naracki, V. (2008). School building condition, school attendance, and academic achievement in New York City public schools: A mediation model. Journal of Environmental Psychology, (28), pp. 278-286. doi:10.1016/j.jenvp.2008.02.008. In Rowena Hay, Flora Samuel, Kelly J. Watson \& Simon Bradbury (2017): Postoccupancy evaluation in architecture: experiences and perspectives from UK practice, Building Research \& Information, UK: Routledge a Taylor \& Francis Group, pp. 1-14. DOI: 10.1080/09613218.2017.1314692 
8. Garcia, J. \& Gustavson, A. R. (1997). The science of self-report. Association for Psychological Science. Retrieved from: https://www.psychologicalscience.org/observer/the-science-of-selfreport

9. Jones, S., \& Grigoriou, E. (2014). Wellbeing matters: Assessing views on the impact of the built environment on wellbeing. London: Feeling Good Foundation. In Rowena Hay, Flora Samuel, Kelly J. Watson \& Simon Bradbury (2017): Post-occupancy evaluation in architecture: experiences and perspectives from UK practice. Building Research \& Information, UK: Routledge a Taylor \& Francis Group, pp. 1-14. DOI: 10.1080/09613218.2017.1314692

10. Kilbourne, J., Scott-Webber, L., \& Kapitula, L.R. (2017). An activitypermissible classroom: Impacts of an evidence-based design solution on student engagement and movement in an elementary school classroom. Children, Youth and Environments 27(1), pp. 112-134.

11. Nissim, Y., Weissblueth, E., Scott-Webber, L. \& Amar, S. (2016). The effect of a new stimulating learning environment on pre-service teachers' motivation and $21^{\text {st }}$ century skills. Journal of Education and Learning. 5(3). p. 29-39. Doi:10.5539/jel.v5n3p29. http://dx.doi.org/10.5539/jel.v5n3p29

12. O’Kelly, M., Scott-Webber, L., \& Garrison, J. (2017). Can a library building's design cue new behaviors? A case study. portal. Libraries and the Academy. 17(4). MD: John Hopkins University Press, pp. 843862.

13. Rowena Hay, Flora Samuel, Kelly J. Watson \& Simon Bradbury (2017): Post- occupancy evaluation in architecture: experiences and perspectives from UK practice. Building Research \& Information, DOI: 10.1080/09613218.2017.1314692

14. Scott-Webber, L. (2014). The perfect storm: education's immediate challenges. In Scott-Webber, L. Branch, J., Bartholomew, P. \& Nygaard, C. (Eds). (2014). Learning space design in higher education. Greece. Libri Publishing. pp. 151-168.

15. Scott-Webber, L., Konyndyk, R., French, R., Lembke, J., \& Kinney, T. (2017). Spatial design makes a difference in student academic engagement levels: A pilot study for grades 9-12. European Scientific Journal, 13(16), ISSN: 1857-7881 Doi: 10.19044/esj.2017.v13n16p5. From: http://eujournal.org/index.php/esj/issue/view/281

16. Scott-Webber, L., Konyndyk, R., French, R., Lembke, J., \& Kinney, T. (2017). Spatial design makes a difference in student academic engagement levels: A pilot study for grades 9-12. European Scientific Journal. 13(16), ISSN: 1857-7881 Doi: 10.19044/esj.2017.v13n16p5. http://eujournal.org/index.php/esj/issue/view/281 
17. Scott-Webber, L., Marini, M., \& Abraham, J. (Spring, 2000). Higher education classrooms fail to meet needs of faculty and students. Journal of Interior Design, 26(1), 16-34.

18. Staff. (2003). Validity of self-report survey data (or "but everyone lied on the survey..."). Center for Health and Safety. Source: Brener ND, Billy JOG, Grady WR. Assessment of factors affecting the validity of self-reported health-risk behavior among adolescents: evidence from the scientific literature [pdf 200K]. Journal of Adolescent Health, 2003, 33, pp. 436- 457. Retrieved from: https://www.minnetonkaschools.org/uploaded/Documents/Dist/Tonk a_Cares/Reveal_What\%27s_Real/Validity_of_Self_Report.pdf

19. Ulrich, R. S. (2008). A review of the research literature on evidencebased healthcare design. HERD, 1, 61-125. doi:10.1177/193758670800100306. In Rowena Hay, Flora Samuel, Kelly J. Watson \& Simon Bradbury (2017): Post-occupancy evaluation in architecture: experiences and perspectives from UK practice, Building Research \& Information, UK: Routledge a Taylor \& Francis Group, pp. 1-14. DOI:10.1080/09613218.2017.1314692

20. Watson, K. J., Evans, J., Karvonen, A., \& Whitley, T. (2016). Reconceiving building design quality: A review of building users in their social context. Indoor and Built Environment, (25), pp. 509523.doi:10.1177/1420326X14557550. In Rowena Hay, Flora Samuel, Kelly J. Watson \& Simon Bradbury (2017): Post-occupancy evaluation in architecture: experiences and perspectives from UK practice, Building Research \& Information, UK: Routledge a Taylor \& Francis Group, pp. 1-14. DOI: 10.1080/09613218.2017.1314692 